\title{
Research on Problems and Solutions of Urban Community Elderly Physical Fitness Services under Healthy Aged Tendency - Take Hubei Province for Example Honglian Guo ${ }^{1, a}$ Hongping Cheng ${ }^{2, b *}$
}

${ }^{1}$ Center of Health Administration and Development Studies, Hubei University of Medicine, Shiyan, Hubei, 442000

\author{
Keywords: Elderly Physic, Community Fitness Services, Dilemma; Healthy Aged Tendency
}

\begin{abstract}
This paper analyzes the current situation of the elderly sports service in the urban community by investigating the status quo of the elderly sports in the urban community of Hubei Province and the investigation of the situation of the elderly sports service in the community by literature, questionnaires, field visits and other methods. From the perspectives of soundness of the old sports regulations, the construction and management of the elderly sports organizations in the community and the development of the fitness habits of the elderly clarify the fundamental way out for the urban community.
\end{abstract}

\section{Introduction}

Since 2003, Hubei began to enter the aging society, the population aging rate gradually accelerated. As of the end of 2013, Hubei Province, 65 years old and above the elderly population has reached 592.22 million, accounting for $10.21 \%$ of the total population of the province [1], the huge elderly population will be the old-age security and socio-political and economic development challenges. The development of the elderly sports, for the elderly to build sports fitness service system, improve the health of the elderly, to achieve "healthy aging", has become a positive response to the challenges of aging inevitable choice. This study is based on the understanding that the elderly sports service in the community is beneficial to the realization of social health and aging, and investigate the current situation of the elderly sports in Hubei city and the plight of the physical fitness service, and seek the countermeasures to provide decision-making for the construction of the elderly sports service in the urban community reference.

\section{Elderly Sports and Healthy Aging}

The so-called "healthy aging" refers to the aging society, the vast majority of the elderly in physical, psychological and social function of the healthy state, so that social development is not affected by excessive population aging [2]. This concept focuses on the healthy lifestyle of the elderly, mentality, social support, medical service system, advocated by the elderly physical, psychological, social and other aspects of coordinated development, with the corresponding policy is emphasized Is the physical health of the elderly, medical services and material living conditions and their psychological feelings, happiness and lifestyle adaptation.

The elderly sports as an important part of the elderly activities, the elderly lifestyle and physical and mental health development, has important significance, the elderly through scientific physical exercise, to prevent disease control, increase social interaction and promote physical and mental health, Thereby improving old age and quality of life. Elderly sports is an important way to achieve healthy aging and the main measures, it is the old age of life impact, the attraction of the strong, the role of other social and cultural activities cannot be compared and replaced, at this point, people have reached a consensus. Therefore, how to strengthen the elderly sports service, to further promote the development of sports in the elderly, and constantly expand the elderly sports population, to a certain extent, affect the process of social health and aging. 


\section{City Community Elderly Sports Development}

The Participation Status of the Elderly Sports. The time and frequency of participation in sports activities is an important basis for ensuring the fitness effect. In the investigation of the time and frequency of physical exercise of the elderly in some urban communities in Hubei Province, it is found that most of the elderly exercise time is abundant and the exercise time is mainly in the morning and evening of which $37 \%$ and $14.2 \%$ of the elderly were selected to exercise in the morning and evening, $46.8 \%$ of the elderly choose to work in the morning and evening two times, including up to 54\% of the elderly to participate in physical exercise every week 3 times and above, each time the exercise time in about 1 hour, we can see that the current urban community awareness of the elderly is gradually increased, to participate in physical exercise more time, frequent high fitness, each exercise a long time.

At the same time, the survey found that the elderly in Hubei urban community to participate in physical exercise in the street side of the road, park square and residential area of the main space to public places, their own homes, etc., supplemented by. Activities are presented with obvious open features. In the form of physical activity, most elderly people choose organized sports activities. Nearly half of the people choose to work with friends and family members, and the elderly are walking on the fitness program, tai chi, aerobics, ball, tai chi and other activities of the intensity of small, easy to control the activities, activities and organization of simple and easy to organize the project, which shows that the elderly groups at this stage spending capacity is weak, free public places and free sports the most elderly welcome, which requires the government to local conditions, do a good job of community sports public services to meet the needs of the elderly sports fitness.

In addition, the survey of elderly people involved in physical exercise survey found that up to $90 \%$ of the respondents believe that physical exercise is necessary, that physical exercise can enhance physical fitness, and that physical exercise after the mood better than before, indicating that the current elderly on their own physical and mental health attention, to participate in the positive attitude of sports, motives clear, self-awareness of physical exercise to enhance the degree of physical fitness needs to improve.

The Demand Status of the Elderly Sports. Sports facilities are to meet the elderly physical fitness activities of the basic material security, from the field visit found that the elderly in Hubei Province, the elderly sports fitness facilities have obvious geographical differences, fitness path construction development is uneven, only part of the community configuration fitness Path, gate court and elderly activity room. At the same time from the questionnaire survey, only $39.8 \%$ of the elderly that the sports public facilities can basically meet the needs of physical fitness, and $82.2 \%$ of the elderly want to lead them to organize their fitness activities, and hope that physical exercise in the social sports instructor their fitness to guide. This shows that the current urban community existing sports venues facilities and fitness services cannot meet the growing needs of the elderly sports fitness, strengthening the community elderly sports public service without delay.

\section{The Main Dilemma of City Community Elderly Sports Fitness Services}

The Legal Regulation of Elderly Sports Is Not Perfect. At present, there are very few laws and regulations and policies related to the protection of old age sports. Although the program of the National Fitness Program has been implemented for more than ten years, the elderly sports population is gradually increasing, but it has not yet formulated the old sports policy. The current policy related to the elderly sports is only scattered in such as "Sports Law", "National Fitness Regulations", "Rights Protection Law for the elderly" and so on the mass sports policy and aging policy, the specific content is small and lack of supporting projects, Making the policy less operable, affecting the implementation of the policy effect, resulting in the allocation of sports resources is not conducive to the development of sports in the elderly, thus becoming one of the bottlenecks restricting the development of sports in the elderly.

Low Level of Socio-Economic Development and Serious Lack of Hardware and Software Facilities. It is always the biggest hidden danger and challenge in the process of modernization of 
our country. The economy is not developed enough, people's living standards are generally not high, while the elderly population increased sharply and lack of funds has become the constraints around the elderly to carry out the most practical work of sports problems. At present, suitable for the activities of the elderly facilities are still relatively backward, the existing fitness venues cannot meet the growing fitness needs of the elderly, while the elderly sports instructors rarely, the quality is not high, many are amateur nature, lack of professional knowledge and skills, scientific and fitness propaganda guidance is not enough, which are seriously affected the quality of the elderly community sports services, restricting the further development of the elderly sports.

The Awareness on the Elderly Sports Is Not Enough and the Elderly Sports Organization Construction Lag Behind. At present, some urban leaders are not aware of the social situation of healthy aging, and it is not in place to ensure the importance of sports fitness in the elderly to protect and improve people's livelihood, promote the construction of spiritual civilization and build a harmonious society, so the work of the elderly attention is not high, on the one hand did not give full play to the leading role of party and government, not the elderly sports work should be placed on the location of the old sports supply and demand is very prominent; on the other hand did not promote the elderly sports organization management, the establishment of a concerted effort of the elderly sports leadership coordination mechanism, activities, organization and management mechanism and funding protection mechanism, the elderly and other sports associations and the role of social organizations is difficult to fully play [3].

Awareness of Self-Care and Awareness of Rights Is Not High. At present, most of our elderly population is not high cultural level, coupled with the traditional ideas and ideas, there are many elderly people to meet the needs of survival, the majority of the financial and energy are concentrated in the next generation, for the pursuit of their own high level to enjoy lack of awareness, to participate in community sports activities do not have too much demand, physical exercise is very casual. Although some of the elderly have gradually increased awareness of the exercise, but due to the geographical location and human environment, the fitness methods and the degree of exercise awareness is far from enough, the community management of elderly sports and service quality requirements are not high did not better enjoy the right to sports public service.

\section{The Fundamental Way of Urban Community Elderly Sports Fitness Services}

Strengthen the Construction and Improvement of Community Old Sports Legal System from the Macro Level. Government departments should first change the concept, attention to the elderly group of fitness activities, give full play to the government's policy design and guiding role, launched the Ministry of Housing Construction, Ministry of Civil Affairs, the elderly and other relevant departments to develop and improve the community sports laws and regulations, laws and regulations In the form of a clear division of various departments at all levels in the community sports responsibilities to protect the community elderly groups of sports public service rights. At the same time should attach great importance to the establishment and improvement of the organization of the elderly sports associations, and actively play the role of the elderly organizations such as the county, street and so on, using a variety of ways to attract and organize more elderly people to participate in sports activities.

Strengthen the Community Old Sports Organizations Construction and Service Management from the Perspective of Medium level. On the one hand, the government should learn from the experience of community sports organizations in foreign and developed areas, combined with the national conditions and conditions, relying on the strength of the community, the use of policy support and financial assistance to promote the development of old sports, and actively develop both public welfare, sex and market-oriented comprehensive community sports organizations to encourage enterprises to participate in the construction of the elderly sports investment, as soon as possible to establish a set of organization and management of the elderly community sports activities of the elderly group fitness service system. On the other hand, according to the needs of the elderly physical fitness and the characteristics of the project, to speed up the construction of elderly sports venues, will build the elderly fitness center, into the provincial 
government and the people's livelihood and happiness projects, while increasing the elderly sports professional instructors of the training efforts to strengthen the management of the elderly community sports service, it is recommended that the elderly sports fitness into the evaluation of advanced community assessment, from the system to be guaranteed.

Strengthen the Elderly Sports Fitness Habits from the Micro Level. Make full use of radio, television, newspapers, exhibition panels and other means to promote the elderly sports work, popularize the elderly fitness knowledge, through the organization of fitness knowledge lectures, to carry out a wealth of community sports activities such as the elderly to strengthen the awareness of the elderly groups, of the education, so that it can use the side of the venue, join the organization around, to participate in activities around.

\section{Acknowledgements}

Fund Project: Supported by Key Research Center for Humanities and Social Sciences in Hubei Province (Hubei University of Medicine)(2015ZD008)

\section{References}

[1] Hubei Provincial Bureau of Statistics. 2013 Hubei population development status analysis [DB / OL]. [2014-07-04]. Http: //www.stats-hb.gov.cn/wzlm/tjbs/qstjbsyxx/109056.htm.

[2] Wang Xueyi. Healthy Aging: the aging of the population countermeasures [J]. Journal of Southwest University for Nationalities: Philosophy and Social Sciences, 2002, 23 (12): 131.

[3] Research on the Strategy of Promoting the Work of Elderly Sports in the View of Public Service [J]. Journal of Guangzhou Physical Education Institute, 2015, 35 (3): 24 